\title{
BMJ Open Protocol for a randomised controlled trial of $90 \%$ kanuka honey versus $5 \%$ aciclovir for the treatment of herpes simplex labialis in the community setting
}

\author{
Alex Semprini, ${ }^{1,2}$ Joseph Singer, ${ }^{1}$ Nicholas Shortt, ${ }^{1}$ Irene Braithwaite, ${ }^{1}$ \\ Richard Beasley, ${ }^{1,2}$ The Pharmacy Research Network
}

To cite: Semprini A, Singer J, Shortt N, et al. Protocol for a randomised controlled trial of $90 \%$ kanuka honey versus $5 \%$ aciclovir for the treatment of herpes simplex labialis in the community setting. BMJ Open 2017;7:e017766. doi:10.1136/ bmjopen-2017-017766

- Prepublication history for this paper is available online. To view these files please visit the journal online (http://dx.doi. org/10.1136/bmjopen-2017017766).

Received 16 May 2017 Revised 19 June 2017 Accepted 22 June 2017

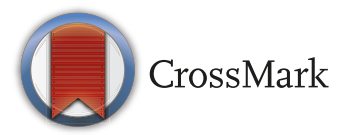

${ }^{1}$ Medical Research Institute of New Zealand, Wellington, New Zealand

${ }^{2}$ Victoria University Wellington, Wellington, New Zealand

Correspondence to

Dr Alex Semprini;

alex.semprini@mrinz.ac.nz

\section{ABSTRACT}

Introduction Worldwide, about $90 \%$ of people are infected with the herpes simplex virus, $30 \%$ of whom will experience recurrent herpes simplex labialis, commonly referred to as 'cold sores', which can last up to 10 days. The most common treatment is aciclovir cream which reduces healing time by just half a day compared with no specific treatment. This is a protocol for a randomised controlled trial (RCT) to determine the efficacy of medical grade kanuka honey-based topical treatment (Honevo) in reducing the healing time and pain of cold sores, compared with topical aciclovir treatment (Viraban).

Methods and analysis This open-label, parallelgroup, active comparator superiority RCT will compare the efficacy of medical grade kanuka honey with $5 \%$ aciclovir cream in the treatment of cold sores in the setting of a pharmacy research network of 60 sites throughout New Zealand. Adults presenting with a cold sore $(\mathrm{N}=950)$ will be randomised by pharmacy-based investigators. The pharmacy-based investigators will dispense the investigational product to randomised participants and both study groups apply the treatment five times daily until their skin returns to normal or for 14 days, whichever occurs first. In response to a daily SMS message, participants complete an assessment of their cold sore healing, with reference to a visual guide, and transmit it to the investigators by a smartphone eDiary in real time. The primary outcome variable is time (in days) from randomisation to return to normal skin. Secondary endpoints include total healing time stratified by stage of the lesion at onset of treatment, highest pain severity and time to pain resolution.

Ethics and dissemination New Zealand Ethics Registration 15/NTB/93. Results will be published in a peer-reviewed medical journal, presented at academic meetings and reported to participants.

Trial registration number Australia New Zealand Clinical Trials Registry: ACTRN12615000648527, preresults. SCOTT Registration: 15/SCOTT/14

Protocol version 4.0 (12 June 2017)
Strengths and limitations of this study

- A novel approach to conducting randomised controlled trials in the community, using a pharmacybased research network and a unique electronic method to improve data collection.

- Presentation to community pharmacies enables recruitment early in the course of the cold sore episode, without delay in arranging formal outpatient research clinic review.

- Establishment of the trained pharmacy network across New Zealand provides potential to widely engage members of the public, thereby enhancing generalisability of the study findings.

- Novel participant self-assessment with reference to a visual severity/healing stage guide and associated electronic data transmission allows for real-time data collection and monitoring without investigatorled visits.

- Treatment allocation cannot be masked to participants due to the physical characteristics of honey.

\section{INTRODUCTION}

Herpes labialis

The herpes simplex virus (HSV) is a pervasive human infection. The global seroprevalence in adults is around $90 \%{ }^{1}$ The orolabial manifestation of disease is herpes simplex labialis (HSL), colloquially known as a 'cold sore'. Recurrent episodes occur in $30 \%$ of those infected and are commonly triggered by stress, fatigue, sunlight and altered immune states. The resulting lesions are painful, unsightly and difficult to treat. Popular therapeutic strategies include oral or topical antiviral agents such as aciclovir, ${ }^{2}{ }^{3}$ local anaesthetic preparations and lysine supplementation. The effectiveness of these treatment options is, at best, modest. The most commonly used therapy is topical aciclovir which reduces 
average healing time by only half a day compared with control treatment. ${ }^{4}$ The natural history of recurrent HSL is a prodrome of tingling and itch, progression to erythema, blistering, ulceration and crusting, before a return to normal skin.

\section{Honey}

Honey has a range of anti-inflammatory as well as antibacterial, antifungal and antiviral effects. ${ }^{5-7}$ These properties have led to the use of medical grade honey in a wide range of conditions. Honey is efficacious in the treatment of wounds, burns, infections and rosacea. ${ }^{8-15}$ There is also preliminary evidence supporting its use in the treatment of HSV from a small randomised controlled trial (RCT) in 16 adult patients with recurrent attacks of herpetic lesions in which topical application of a multiflora honey appeared to be more effective than 5\% aciclovir cream for HSL and genital herpes. ${ }^{16}$ The mean healing time for HSL and genital herpes was 3 days shorter for honey compared with aciclovir, 2.6 compared with 5.9 days (95\% CI 1.6 to $3.52, \mathrm{p}<0.05)$. Whether the efficacy of the honey product was due to antiviral effects, which have been demonstrated against HSV in vitro ${ }^{77}$ and/or the numerous immunomodulatory effects which have been demonstrated in both in vivo and in vitro, was not assessed in this study. ${ }^{10}$ Prior to undertaking a large RCT to validate these findings, we performed a feasibility study of the use of New Zealand kanuka honey in the treatment of recurrent cold sores in general practice. ${ }^{18}$ We found that although topical medical grade kanuka honey was well tolerated and highly acceptable to patients, a novel study design would be required to undertake a definitive RCT that was adequately powered to determine a clinically relevant therapeutic effect. In particular, we identified that the RCT would need to have the following features: (1) an alternative recruitment strategy, such as provided by community pharmacies, where potential participants commonly present for common ailments and in which medication can be obtained without prescription; (2) less restrictive inclusion/exclusion criteria to enhance recruitment and increase generalisability of findings; (3) a parallel group rather than crossover design with block randomisation by site using computer-generated sequence; (4) closer ongoing supervision of treatment and documentation of outcomes using novel techniques based on mobile phone systems gathering real-time data and (5) a pharmaceutical grade honey product that does not melt at body temperature so that application does not require gauze.

These features are incorporated in the design of the RCT described in this paper. Specific novel features include: (1) use of selected pharmacies which receive intensive Good Clinical Practice (GCP) training to recruit participants; (2) repeated daily self-assessment by participants of the severity and healing of their cold sores with reference to a visual guide; (3) smartphones with reminder functions to transmit daily clinical information in real time and (4) use of a medical grade $90 \%$ kanuka honey/10\% glycerin cream (Honevo) with greater heat stability. These methodological features of the study have the potential to achieve more complete and valid data collection than previous RCTs of HSL undertaken in clinics using paper diaries. ${ }^{19-21}$

\section{Aim}

To determine the safety and efficacy of topical $90 \%$ kanuka honey/10\%/glycerin (Honevo) compared with topical $5 \%$ aciclovir cream in the treatment of HSL.

Hypothesis

Ninety per cent kanuka/10\% glycerin (Honevo) has a greater efficacy compared with topical $5 \%$ aciclovir for the management of HSL.

\section{METHODS AND ANALYSIS \\ Study design}

An open-label, parallel-group, superiority RCT of the efficacy of medical grade kanuka honey (Honevo) compared with 5\% aciclovir (Viraban) in the topical treatment of HSL in adults. The protocol has been developed in accordance with Standard Protocol Items: Recommendations for Interventional Trials (SPIRIT) guidelines. ${ }^{22}$

\section{Participants}

Adults aged $>16$ years who present to a community pharmacy for treatment of a cold sore will be screened for eligibility. The key inclusion criterion is the onset of first symptoms within 72 hours of presentation (box 1).

\section{Screening and selection}

Participants presenting to one of the pharmacy localities (figure 1) for the treatment of a cold sore will be offered the opportunity to participate in the trial and, if in agreement, undertake eligibility assessment, consent and randomisation followed by dispensing of the investigational product by the pharmacy investigator. Clinical data will be obtained by the pharmacy investigator at enrolment. The consent and baseline participant characteristic and contact details worksheet will be transmitted digitally by secure pdf conversion to the coordinating investigator.

\section{Box 1 Inclusion and exclusion criteria}

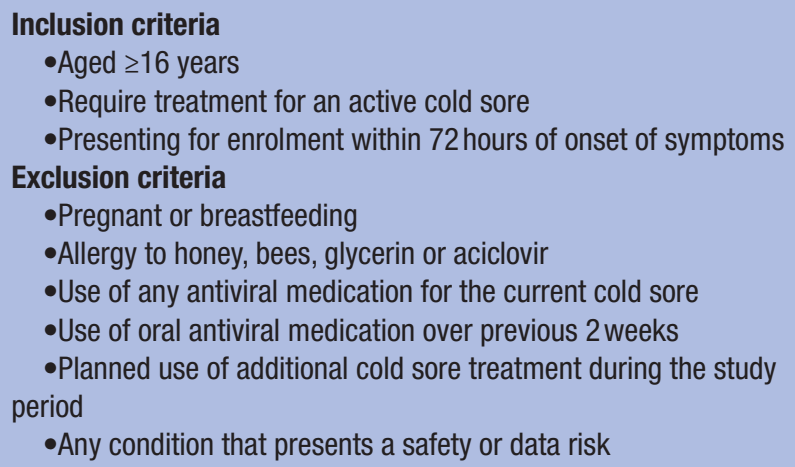




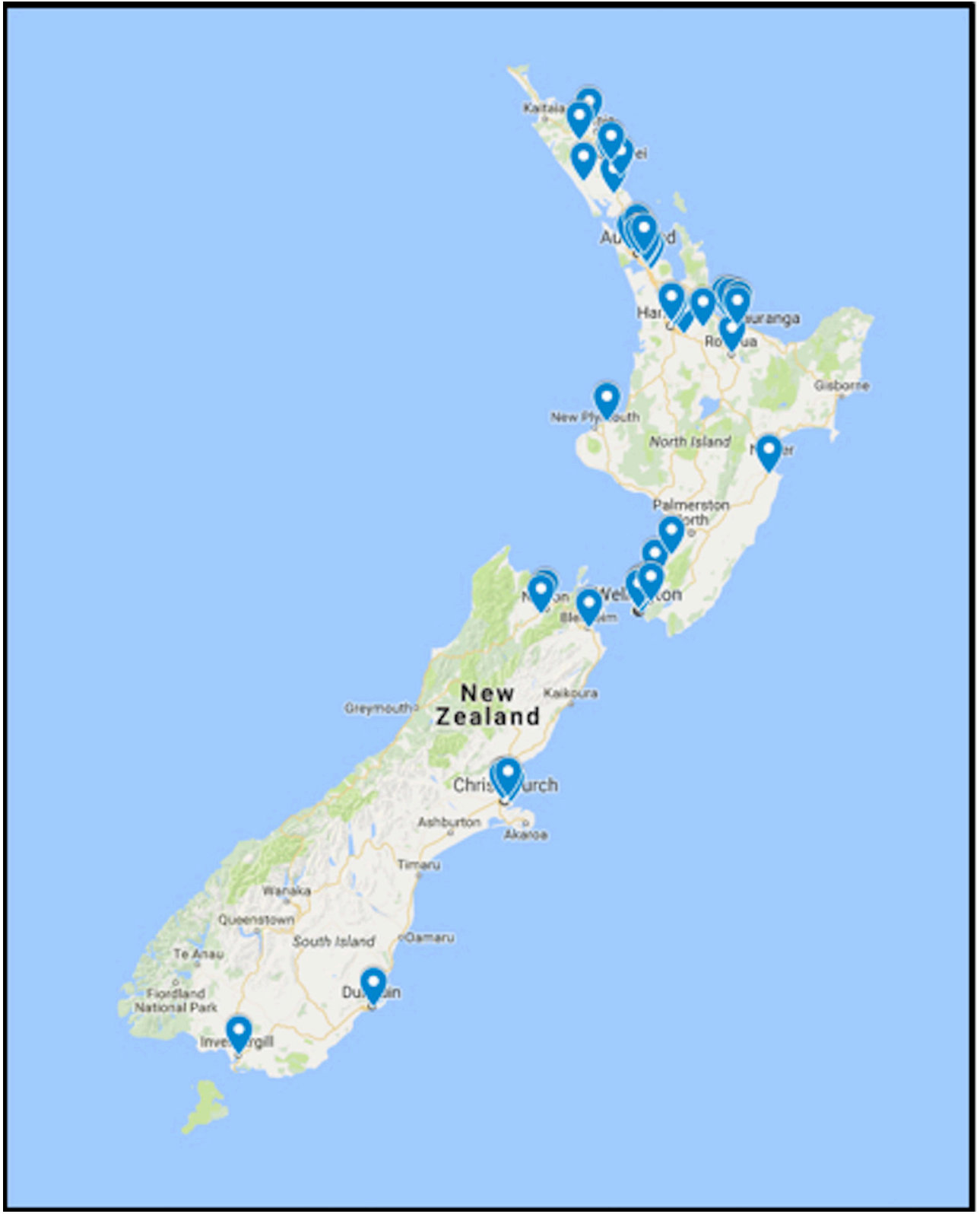

Figure 1 The distribution of the pharmacy research network.

\section{Randomisation}

Participants who meet eligibility criteria and give informed consent are randomised 1:1 to receive either $5 \%$ aciclovir or Honevo according to a computer-generated sequence, with a block size of four per site, provided by the study statistician, independent of the coordinating and pharmacy-based investigators. Each site will be provided with specific randomisation identifiers contained within opaque envelopes, opened only at the time of participant enrolment. As Honevo is impossible to mask, due to the smell and taste of the honey, participants will not be able to be blinded as to their treatment allocation. Allocation will be concealed within a secure database containing the randomisation sequence, only revealed to the coordinating researcher for adverse events and data analysis on study completion.
Interventional treatments

The interventional treatments are Honevo, a topical medical grade $90 \%$ kanuka honey/10\% glycerin cream, and Viraban, a $5 \%$ aciclovir cream. Treatment application schedules are identical for each study arm. Participants will be instructed to apply the treatment five times daily until their skin returns to normal as per a visual healing chart (figure 2) or until 14 days have passed, whichever occurs first.

\section{Data capture and monitoring}

Participant enrolment data will be logged and a short message (or messaging) service (SMS) sequencer triggered, within which a daily, unique and autovalidated link is embedded to a smartphone-rendered eDiary (figure 2). The participant will complete an assessment of their cold sore healing in response to a daily 'SMS' 


\section{MEDICAL RESEARCH}

INSTITUTE

\section{Cold Sore Study eDiary Day 1}

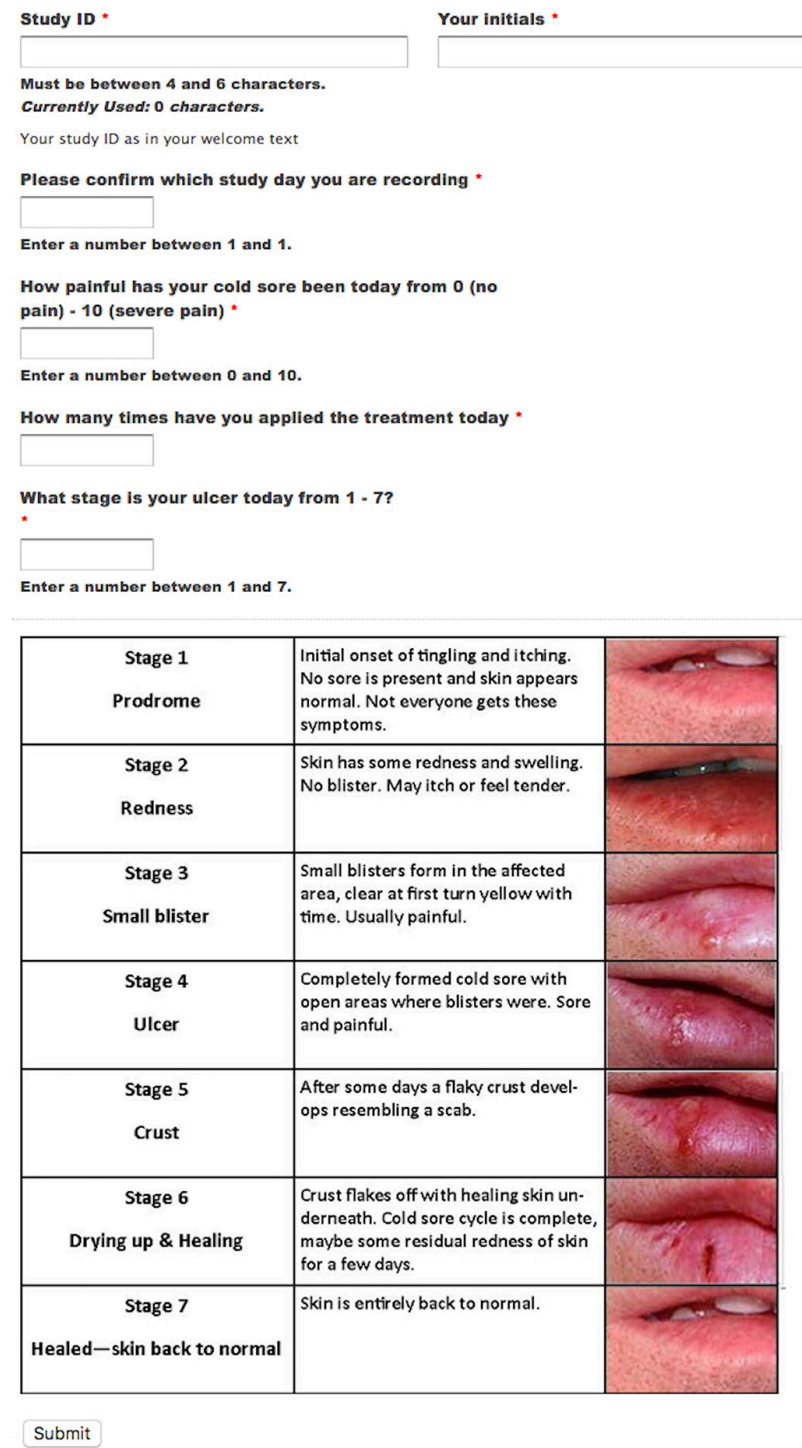

Figure 2 Diary link with herpes simplex labialis severity and healing staging system. message, including visual severity and healing stage assessment daily for either 14 days or until the skin returns to normal. The daily data (pain, healing stage and number of applications) will be reconciled by a second investigator, immediately available for monitoring and ensures maximal adherence, thereby reducing loss to follow-up. Entry of a fully healed cold sore stage triggers a notification and further SMS are stopped. For participants who withdraw or do not complete the study, all data collected will be used for outcome analysis. All data will be securely held on the study team database, accessible only by authorised investigators for the purposes of monitoring. The final dataset will be accessible by the coordinating investigators and each locality will retain on-site access to digital copies of source documentations with paper copies stored in secure archives. A specific study monitoring plan, independent from the Sponsor, is in place to ensure all study conduct complies with International Council for Harmonisation of Technical Requirements for Registration of Pharmaceuticals for Human Use, GCP and New Zealand ethical guidelines. All substantial protocol deviations and violations will be reported to the New Zealand ethics committee as per approval requirements.

\section{Follow-up assessments}

A telephone follow-up is scheduled for day 15 to assess adverse events and acceptability of treatment (figure 3). If unsuccessful, a further attempt is made the next day and at day 22. If a scheduled attempt falls on a holiday or weekend, it is conducted the following working day. Further attempts to contact participants may be made after this by the study coordinators via text, email or telephone call within 3 weeks of day 14 .

Outcome measures

Primary

Healing time from randomisation to the return to normal skin, measured in days.

\section{Secondary}

(1) Total healing time (days), defined as time from development of first sign or symptom to the return to normal

Figure 3 Study timeline.

\begin{tabular}{ccc}
\hline Visit 1 & $\begin{array}{c}\text { Daily diary entries } \\
\text { Pain, applications, stage of healing }\end{array}$ & Visit 2 \\
Pharmacy enrolment & Follow up \\
Randomisation, & Safety review, \\
treatment & acceptability, \\
dispensation & comments
\end{tabular}

Day 0

Day 1 to 14

Day 15 to 35

Figure 3: Study timeline 
skin. (2) Total healing time (days) stratified by stage of the lesion at onset of treatment. (3) Highest pain severity. (4) Time to pain resolution (days), defined as time from first experiencing pain to total resolution of pain. (5) Time to stage 4 from randomisation. (6) Time to stage 7 from stage 4. (7) Acceptability of treatments.

\section{Statistical analysis}

This will be by both intention to treat and per protocol analysis and will use, as the primary analysis, Kaplan-Meier survival plots, estimates of median healing times and Cox proportional hazards for time to healing and pain duration to compare the treatments. For the secondary outcomes which are continuous, variables t-tests will be used. Sensitivity analyses will be performed for both primary and secondary outcome variables, considering important potential confounders such as age, time to presentation from reported onset of symptoms and stage of cold sore at presentation. Interaction analyses will be performed for primary and secondary outcome variables, to assess potential differences in treatment effects for potential effect modifiers.

\section{Power calculation}

The median duration of symptoms is 5 days with aciclovir. ${ }^{4}$ Based on this study, to have $90 \%$ power to determine a 1-day median difference, with associated HR of 1.25, 423 participants need to be recruited in each arm of the RCT. If the dropout rate is $10 \%$, then 950 participants are required to be randomised.

\section{Ethics, study registration and dissemination}

National ethical and SCOTT approval has been obtained for all currently active recruiting sites and the trial is registered with the Australia New Zealand Clinical Trials Registry. Results will be published in international academic journals and presented at conferences. Participants will receive summarised results of the publication.

\section{Participant safety}

Adverse events and serious adverse events will be reviewed by the coordinating team within 24 hours of reporting and annual safety reporting to the ethics committee will take place, as per approval.

An independent data safety monitoring board convened after the first 100 participants and reported no major concerns. The addition of bee allergy to the exclusion criteria was recommended and subsequently added.

Full indemnity insurance is in place for the study sponsor in the case of claims resulting from trial participation.

Collaborators Pharmacy Research Network: John Castle Chemist: Shahlaa Al Salih and Noor Al Rawe; Countdown Pharmacy Newtown: Eddie See and Raksha Goundar; Life Pharmacy Tauranga: Garth Mitchinson; Countdown Pharmacy Petone: Nimmi Gnanasekaran; Countdown Pharmacy Cambridge: Vish Gangapuri; University of Waikato Pharmacy: Kerry Dean; Cook St Pharmacy: Anthony Roberts and Anne Lim; Alexander Pharmacy: Angela Liu, Lorraine Brunton and Kate Adam; Countdown Pharmacy Eastgate: Michelle Hwang; Countdown Pharmacy Church Corner: Henriette Meyer, Outi Kolju, Tyler Pornchaisuksiri and Mate Hegedus- Gaspar; The Pharmacy@Phillipstown: Ruby Willing and Shirin Namjou; The Pharmacy @ St Georges: Ray Sefton; Pharmacy@Ferrymead: Grant Bell and Nehad Kamel;
University of Canterbury Pharmacy: Lesley Robertson; The Dispensary 914: Angela Blackwood; Life Pharmacy Coastlands: Debora Nguy; Life Pharmacy Kilbirnie: Androulla Kotrostos; Victoria University Pharmacy: Melanie Wong, Sascha Ion, Alice Manch and William Gin; Unichem Johnsonville: Matthew Grey, Dipika Parmar and Maureen Raju; Crofton Downs Pharmacy: Karen Rich and Catherine Hosler; Unichem Karori Mall: Brian Johnston; Unichem Owles Naenae: Patrick Lim and Janet Downing; Unichem Guys: Chau Ly and Alice Liu; Unichem Leabank: Kerry Oxenham, Yolanda Savage and Navjot Kaw; Unichem Greenlane: Chris Wrapson and Danielle Stewart; Unichem Milford: Julie Earwaker; Westgate Pharmacy: Rav Singh; Unichem Apollo: Elisabeth Lubbe; Unichem Riccarton Clinic: Jim Sherborne, Chuck Varghese, Hayley Garvin, Nicholas Tee, Kelly Burgess and Shuyi Zhang; Unichem Levin: Malli Kotali and Ingrid Nickson; Bay Plaza Pharmacy Hastings: Peter Neal and Natasha Roughton; Life Pharmacy Howick: Leane Steele; Life Pharmacy Manukau: Kritika Singh; Wairau Pharmacy Blenheim: Joanna Topliss, Kayleigh Mackel, Claire Livingstone, Joy Birch, Marion Gray, Sally Rudie and Robyn Morrison; Life Pharmacy Chartwell: Glenn Summerville, Neville Puckley, Lorina Lu, Jenni Puckley and Shilpa Narain; Unichem Rotoruna: Jenny Wu, Shazeel Rauf, Angeline DayMesuré and Jordan Hinton; Ranolf Pharmacy Rotorua: Charlotte Schimanski and Carina Soeteman; Unichem Cherrywood: Rachelle Smith and Sam Appleford; Life Pharmacy Bayfair: Linda Southby; Mypharmacy Papamoa: Reece Olsen, Delphine Destrez, Michelle Speirs and Jordan Jeffray; Harley's Pharmacy Tahunanui: Violet Harley; McGlashen Pharmacy Nelson: Andrew McGlashen; Unichem Excelsa: Cassie Butler, Sonia Schwamm, Jacqui Brus and Alaina van Zyl; Life Pharmacy Matamata: Jess Ensor and Aidan Kortegast; South City Pharmacy Invercargill: Steve Jo, Eric Li, Jenna Ludlow and Zheng Li; Unichem Cashel Street: Brendon McIntosh and Annabel Turley; Countdown Ponsonby: Eddie See; Waitara Pharmacy: Margaret Helms, Ashley Cronin, Kelly Shearer, Leanne Herbert, Kadyn Lowe, Corry Bezems, Deb Laurence, Chantelle Kissick, Wendy Purkes, Sheryl Montgomerie, Fiona McLachlan, Amanda Barkley and Cathy Hight; Unichem Kaikohe: Alexander Graham, Jilly Alexander and Lara Blaikie; Davids Pharmacy Whangarei: David Postlewaight; Unichem Kerikeri: Vicki Douglas and Ingrid Reed; Life Pharmacy the Palms:Karen Chen, Malinda Ouk, Jan Green, Jackie Jamieson, Linda Herman, Debra Clutterback, Sultana Zannat, Sharon Sullivan and Lucy Armstrong; Orrs Unichem Ruakaka: Warren Greene; Orrs Unichem Tui: Donnie Yoh; Orrs Unichem Dargavaille: Marcus Liddle; Orrs Unichem Maungaturoto: Simerjeet Saini; Life Pharmacy Eastridge: Saif Al-Sheibani and Lisa Josephs; Andersons Pharmacy Dunedin: Bob Kim; Life Pharmacy Te Puke: Renee Belling, Deborah Ellison, Abbie Copinga and Julie Summers.

Contributors AS, IB and RB: designed the study. AS, JS and NS: manage the study participants and data. AS and RB: drafted the manuscript. All authors: reviewed and edited the manuscript drafts.

Funding HoneyLab, Tauranga, New Zealand.

Competing interests None declared.

Ethics approval NZ Ethics Registration 15/NTB/93.

Provenance and peer review Not commissioned; externally peer reviewed.

Open Access This is an Open Access article distributed in accordance with the Creative Commons Attribution Non Commercial (CC BY-NC 4.0) license, which permits others to distribute, remix, adapt, build upon this work non-commercially, and license their derivative works on different terms, provided the original work is properly cited and the use is non-commercial. See: http://creativecommons.org/ licenses/by-nc/4.0/

(C) Article author(s) (or their employer(s) unless otherwise stated in the text of the article) 2017. All rights reserved. No commercial use is permitted unless otherwise expressly granted.

\section{REFERENCES}

1. Wald A, Corey L. ersistence in the population: epidemiology, transmission. In: Human Herpesviruses: Biology, Therapy, and Immunoprophylaxis. Cambridge: Cambridge University Press, 2007.

2. Cernik C, Gallina K, Brodell RT. The treatment of herpes simplex infections: an evidence-based review. Arch Intern Med 2008;168:1137-44.

3. Arduino PG, Porter SR. Oral and perioral herpes simplex virus type 1 (HSV-1) infection: review of its management. Oral Dis 2006;12:254-70.

4. Spruance SL, Nett R, Marbury T, et al. Acyclovir cream for treatment of herpes simplex labialis: results of two randomized, double-blind, vehicle-controlled, multicenter clinical trials. Antimicrob Agents Chemother 2002;46:2238-43. 
5. Kwakman PH, Zaat SA. Antibacterial components of honey. IUBMB Life 2012;64:48-55.

6. Irish J, Carter D a, Shokohi T, et al. Honey has an antifungal effect against candida species. Med Mycol 2005;2006:289-91.

7. Hashemipour MA, Tavakolineghad Z, Arabzadeh SA, et al. Antiviral activities of Honey, Royal Jelly, and Acyclovir against HSV-1. Wounds 2014;26:47-54.

8. Molan PC. The evidence supporting the use of honey as a wound dressing. Int J Low Extrem Wounds 2006;5:40-54.

9. Burlando B, Cornara L. Honey in dermatology and skin care: a review. J Cosmet Dermatol 2013;12:306-13.

10. Majtan J. Honey: an immunomodulator in wound healing. Wound Repair Regen 2014;22:187-92.

11. Cooper RA, Molan PC, Harding KG. Antibacterial activity of honey against strains of Staphylococcus aureus from infected wounds. J $R$ Soc Med 1999;92:283-5.

12. Braithwaite I, Hunt A, Riley J, et al. Randomised controlled trial of topical kanuka honey for the treatment of rosacea. BMJ Open 2015;5:e007651.

13. Miguel MG, Antunes MD, Faleiro ML. Honey as a complementary medicine. Integr Med Insights 2017;12.

14. Saikaly SK, Khachemoune A. Honey and Wound Healing : an Update. 2017:237-51.

15. Zbuchea A. Up-to-date use of honey for Burns treatment. Ann Burns Fire Disasters 2014;27:22-30.
16. Al-Waili NS. Topical honey application vs. acyclovir for the treatment of recurrent herpes simplex lesions. Med Sci Monit 2004;10:MT94-8.

17. Ghapanchi J, Moattari A, Tadbir AA, et al. The In Vitro Anti2Viral Activity of Honey on Type 1 Herpes Simplex Virus Assistant Professor, Department of Oral Medicine, School of Dentistry , Shiraz University of Medical. Aust J Basic App/ Sci 2011;5:849-52.

18. Fingleton J, Corin A, Sheahan D, et al. Randomised controlled trial of topical kanuka honey for the treatment of cold sores. Adv Integr Med 2014;1:119-23.

19. Skulason S, Holbrook WP, Thormar $\mathrm{H}$, et al. A study of the clinical activity of a gel combining monocaprin and doxycycline : a novel treatment for herpes labialis. 2012:61-7.

20. Horwitz E, Pisanty S, Czerninski R, et al. A clinical evaluation of a novel liposomal carrier for acyclovir in the topical treatment of recurrent herpes labialis. Oral Surg Oral Med Oral Pathol Oral Radiol Endod 1999;87:700-5.

21. Raborn GW, McGaw WT, Grace M, et al. Oral acyclovir and herpes labialis: a randomized, double-blind, placebo-controlled study. J Am Dent Assoc 1987;115:38-42.

22. Hro A, Mann H, Dickersin K, et al. Research and Reporting methods annals of internal medicine SPIRIT 2013 Statement : defining Standard Protocol items for clinical trials. 1, 2015. 